\title{
NEUROPHYSIOLOGICAL ABNORMALITIES OF THE CENTRAL NERVOUS SYSTEM IN PATIENTS WITH METHAMPHETAMINE PSYCHOSIS
}

\author{
Takushiro Akata, Fumio Kubota, Sadamu Sekiguchi* \\ Department of Neuropsychiatry, Gunma University School of Medicine \\ *Department of Psychiatry, Jomo Hospital
}

\begin{abstract}
To elucidate brain dysfunction in patients with methamphetamine psychosis, we examined background EEG activities by means of the frequency analysis, P300 of auditory event-related potentials and the auditory brainstem evoked response (ABR) in 17 patients and 35 normal controls. The patients were divided into two subgroups according to their symptomatology in the acute stage of psychosis: the hallucination-delusion group of 10 patients who had experienced paranoid delusions and hallucinations and the psychomotor excitement group of 7 patients who had exhibited a severe catatonia-like excitement but had never experienced hallucinations or delusions. Abnormalities found in the patients were as follows: 1) The total powers were decreased in $\delta, \theta$ and $\alpha_{2}$ frequency bands; the decrease was most prominent in the $\alpha_{2}$ band and more pronounced in the psychomotor excitement group. 2) P300 amplitudes were decreased; the decrease was found only in the hallucination-delusion group. 3) ABR latencies were increased, particularly for wave $\mathrm{V}$ and waves $\mathrm{V}$ - I inter-peak interval; the delay was more marked in the hallucination-delusion group. The findings suggest that the cortical dysfunction is mainly involved in the psychomotor excitement group, while the subcortical dysfunction in the hallucinationdelusion group.
\end{abstract}

Key words: Methamphetamine psychosis, EEG background activity, P300, ABR

(Kitakanto Med.J. 48 (2) : 127 136, 1998)

\section{INTRODUCTION}

Methamphetamine is the most potent of sympathomimetic psychostimulants and the intravenous application of it has a strong psychic dependence producing effect comparable to that of cocaine ${ }^{1,2}$. Thus it has so far been widely abused, and it is now well known that the long-term repetitive abuse of it produces a variety of mental and behavioral disorders including methamphetamine psychosis.

Methamphetamine psychosis evolving as a result of chronic intoxication of the drug closely resembles paranoid schizophrenia in the following three points: 1) an episode of acute hallucinatory-delusional psychosis ; 2) personality changes in the residual stage mainly comprising flattened affect and decreased volition; and 3) high relapse liability of psychotic episodes, which easily recur after a few reuse of the drug, alcohol ingestion or even under the non-specific psychological stress. These clinical similarities have attracted interest of researchers to regard methamphetamine psychosis as a model of schizophrenia. This idea postulates that some common pathogenesis may exist in both conditions. At the same time, it has opened a way to animal experiments, since behavioral disorders in animals chronically intoxicated by methamphetamine are homologous to those in human addicts ${ }^{11}$.

Animal experiments on chronic methamphetamine intoxication performed thus far have included enzymological studies of carbohydrate metabolism ${ }^{3)}$, histopathological studies by light and electron microscopy $^{4 \sim 7)}$, studies on behavioral abnormalities ${ }^{1,8 \sim 10)}$, and studies on pharmacological and physiological mechanisms of reverse tolerance or behavior sensitization to the drug ${ }^{11 \sim 13)}$. Clinical human research has included studies in which psychostimulants were experimentally 
readministered to former abusers ${ }^{14 \sim 16)}$, studies on carbohydrate metabolism ${ }^{17,18)}$, studies on eye movements ${ }^{19,20)}$, and studies on event-related potentials ${ }^{21,22)}$. Thus, although a variety of research has been performed on psychostimulant intoxication and psychostimulant psychosis, there has been less research in the physiological field than in other fields, and there have been especially few reports on humans.

The purpose of our study was to conduct a comprehensive physiological evaluation of the central nervous system in patients with methamphetamine psychosis and to elucidate the functional abnormalities of the brain induced by methamphetamine. A wide variety of methods are available to physiologically test the cerebral dysfunction. In the present study we performed a frequency analysis of basic background EEG activity to examine brain function as a whole, and used the late-positive component positive-300 (P300) of the event-related potentials to examine higher brain function and the auditory brainstem response (ABR) to evaluate function in the brainstem. We also discussed the results of these examinations in relation to patient characteristics.

\section{SUBJECTS}

The subjects were 17 of the patients diagnosed as having methamphetamine psychosis at Gunma Prefectural Sawa Hospital between March 1995 and March 1996, who had taken methamphetamine at least once a month for a minimum of 24 months (methamphetamine psychosis group ; all male, mean age $\pm S D$ : $34.4 \pm 9.8$ years, range 19-48 years), and 35 normal volunteers as controls (control group; all male, mean age $\pm S D: 30.0 \pm 9.0$ years, range $21-50$ years). The difference in age between the 2 groups was not significant. The clinical features of the patients are shown in Table 1. The duration of abuse ranged from 2 years 11 months to 29 years 9 months. The patients were classified into two subgroups according to the symptomatology in the acute stage of chronic methamphetamine intoxication. Ten patients were in a hallucinatory-delusional state at their first visit to the hospital, experiencing paranoid delusions of reference and persecution, auditory hallucinations, and visual hallucinations (hallucination-delusion group; mean age $\pm S D: 32.8 \pm 10.0$ years), 6 of whom had experienced flashbacks of the psychotic symptoms. The other 7 patients were in a state of severe catatonia-like excitement, but had never experienced hallucinations or delusions (psychomotor excitement group; mean age $\pm S D: 36.6 \pm 8.3$ years), 4 of whom had shown the flashback phenomenon of excitement. The EEG examinations were performed 2-3 months after the start of treatment when the psychosis had remitted except in two patients. The auditory hallucinations in Case 2 and the paranoid delusions of reference in Case 8 were much ameliorated but still lingering. When the patients were tested, only one patient was off medication, while the rest were on antipsychotic drugs. None of the patients had any abnormal neurological manifestations. A CT study of the head was performed except for Cases 4, 13 and 14, and the only abnormal findings detected were mild cerebral atrophy in Cases 2, 8 and 17. No hearing abnormalities were detected in any of the subjects. Informed consent was obtained from all of the subjects.

Table 1. The clinical features of the methamphetamine psychotic patients

\begin{tabular}{|c|c|c|c|c|c|}
\hline Case & $\begin{array}{l}\text { Age } \\
\text { (year) }\end{array}$ & $\begin{array}{l}\text { Duration of abuse } \\
\text { (year, month) }\end{array}$ & $\begin{array}{l}\text { Mental state } \\
\text { during abuse }\end{array}$ & $\begin{array}{l}\text { Mental state at } \\
\text { EEG examination }\end{array}$ & Brain $\mathrm{CT}$ findings \\
\hline 1 & 19 & $2 \mathrm{yr} 11 \mathrm{mo}$ & HD & remitted & nothing particular \\
\hline 2 & 30 & $12 \mathrm{yr}$ & HD & hallucinatory & slightly atrophic \\
\hline 3 & 46 & $21 \mathrm{yr} 8 \mathrm{mo}$ & HD & remitted & nothing particular \\
\hline 4 & 30 & $10 \mathrm{yr} 3 \mathrm{mo}$ & HD & remitted & not examined \\
\hline 5 & 21 & $3 y r 8 m o$ & HD & remitted & nothing particular \\
\hline 6 & 21 & $3 \mathrm{yr} 10 \mathrm{mo}$ & HD & remitted & nothing particular \\
\hline 7 & 35 & $6 y r 11 \mathrm{mo}$ & HD & remitted & nothing particular \\
\hline 8 & 43 & $24 \mathrm{yr} 7 \mathrm{mo}$ & HD & delusional & slightly atrophic \\
\hline 9 & 35 & $17 \mathrm{yr} 4 \mathrm{mo}$ & HD & remitted & nothing particular \\
\hline 10 & 48 & $29 \mathrm{yr} 9 \mathrm{mo}$ & HD & remitted & nothing particular \\
\hline 11 & 47 & $26 \mathrm{yr} 11 \mathrm{mo}$ & PME & remitted & nothing particular \\
\hline 12 & 42 & $18 \mathrm{yr} 11 \mathrm{mo}$ & PME & remitted & nothing particular \\
\hline 13 & 24 & $7 \mathrm{yr}$ & PME & remitted & not examined \\
\hline 14 & 35 & $15 \mathrm{yr} 4 \mathrm{mo}$ & PME & remitted & not examined \\
\hline 15 & 30 & $9 y r 3 m o$ & PME & remitted & nothing particular \\
\hline 16 & 31 & $12 \mathrm{yr} 4 \mathrm{mo}$ & PME & remitted & nothing particular \\
\hline 17 & 47 & $27 \mathrm{yr}$ & PME & remitted & slightly atrophic \\
\hline
\end{tabular}

HD : hallucinatory-delusional state ; PME : state of psychomotor excitement 


\section{METHODS}

The EEG examinations were carried out using an EEG mapping system MCE-5100 (Nihon Kohden). The order of testing was basic background EEG activity, P300, and then ABR. Acoustic stimulation was applied with a SMP-4100 (Nihon Kohden). The t-test was used for the inter-group comparisons. Spearman correlation coefficients were determined for the period from the start of abuse up until the examination in the present study, the dose of the antipsychotic drugs, and each of the variables in the results of the tests. The doses of the antipsychotic drugs being taken at the time of the test were converted to chlorpromazine equivalents ${ }^{23)}$. The mean dose $\pm \mathrm{SD}$ was $701 \pm 598 \mathrm{mg}$ for the total group, $750 \pm 543 \mathrm{mg}$ for the hallucinationdelusion group and $630 \pm 707 \mathrm{mg}$ for the psychomotor excitement group.

\section{Background EEG activity}

Active electrodes were placed on 16 sites $\left(\mathrm{Fp}_{1}, \mathrm{Fp}_{2}\right.$, $\mathrm{F}_{3}, \mathrm{~F}_{4}, \mathrm{Fz}, \mathrm{F}_{7}, \mathrm{~F}_{8}, \mathrm{C}_{3}, \mathrm{C}_{4}, \mathrm{~T}_{5}, \mathrm{~T}_{6}, \mathrm{P}_{3}, \mathrm{P}_{4}, \mathrm{Pz}, \mathrm{O}_{1}$ and $\mathrm{O}_{2}$ ) in accordance with the International Electrode Placement (10-20 Method) and referred to linked earlobes, with the forehead used as the ground. The band-pass filter frequency was $0.5-120 \mathrm{~Hz}$. The EEG was recorded with the subject resting awake with eyes closed. The portions where the arousal level was high and where inspection revealed no artifacts were analyzed at 10second intervals. Analog-digital conversion and fast Fourier transformation of the EEG was performed with an MCE-5100, and the power was calculated in $0.2 \mathrm{~Hz}$ increments. Using a Nihon Kohden waveform display program $\mathrm{QP}-160 \mathrm{~B}$, the total power values were calculated according to the 6 frequency bands of background EEG activity, i.e., $\delta(2.0 \mathrm{~Hz}$ to less than $4.0 \mathrm{~Hz}), \theta(4.0$ to less than $8.0 \mathrm{~Hz}), \alpha_{1}(8.0$ to less than $10.0 \mathrm{~Hz}), \alpha_{2}$ (10.0 to less than $\left.13.0 \mathrm{~Hz}\right), \beta_{1}(13.0$ to less than $20.0 \mathrm{~Hz})$ and $\beta_{2}(20.0$ to less than $30.0 \mathrm{~Hz})$.

\section{2. $\mathbf{P 3 0 0}$}

The P300 measurements were made by using the odd-ball task in accordance with the guidelines of the Japan Society of Electroencephalography and Electromyography ${ }^{24)}$ (sound pressure: $70 \mathrm{~dB}$, duration: $100 \mathrm{~ms})$, and the target sound $(1,000 \mathrm{~Hz})$ and non-target sound $(2,000 \mathrm{~Hz})$ were randomly presented through headphones in a ratio of $1: 4$. The stimulus interval was also random, with a mean inter-stimulus interval of 1.5 seconds. The subjects were asked to press the button as soon as they heard the target sound. The active electrodes were placed on $\mathrm{Fz}, \mathrm{Cz}$ and $\mathrm{Pz}$, and referred to linked earlobes, with the forehead used as the ground. The electrooculogram (EOG) was recorded from the electrode placed on the right supraorbital ridge. The band-pass filter frequency was $1.5-60 \mathrm{~Hz}$, and the analysis time 1 second. An average of 40 responses not interfered by large EOGs was used for measuring the button-press response time, $\mathrm{Fz}, \mathrm{Cz}$, and $\mathrm{Pz}$ latencies and amplitudes.

\section{3. $\mathbf{A B R}$}

The ABR measurements were made by using a click as the stimulus sound (sound pressure: $90 \mathrm{~dB}$, duration: $0.1 \mathrm{~ms}$, stimulus interval: 10 times a second). The left and right ear was stimulated separately, while the opposite ear was exposed to white noise. The active electrodes were positioned on the right or left earlobe, referred to $\mathrm{Cz}$ with the forehead used as the ground. The band-pass filter frequency was 100 $-3,000 \mathrm{~Hz}$, and the analysis time $10 \mathrm{~ms}$. The average of 1,500 responses was used to measure the peak latencies of waves $\mathrm{I}$ to $\mathrm{V}$ and the inter-peak latency of waves $\mathrm{V}$ - I .

\section{RESULTS}

\section{Background EEG activity}

Representative records of the background EEG activity in a patient with methamphetamine psychosis and a control subject are shown in Fig. 1. On visual inspection, none of the subjects in either group showed abnormal findings, such as prominent slow waves or spikes. Generally, the $\alpha$ waves in the methamphetamine psychosis group had a lower appearance rate and were of a smaller amplitude than those in the control group.

Results of comparison of the total power values for the 6 frequency bands at the 16 locations between the methamphetamine psychosis group and the control group are shown in Table 2. In the patient group, none of the total powers was significantly increased, but the total powers were significantly decreased at 14 sections as indicated by the asterisk on Table 2 : for the $\delta$ power at $\mathrm{C}_{3}, \mathrm{C}_{4}, \mathrm{~T}_{5}$, and $\mathrm{T}_{6}$, for the $\theta$ power at $\mathrm{T}_{6}$, and for the $\alpha_{2}$ power at $\mathrm{F}_{3}, \mathrm{~F}_{4}, \mathrm{C}_{4}, \mathrm{~T}_{5}, \mathrm{~T}_{6}, \mathrm{P}_{3}, \mathrm{P}_{4}$, $\mathrm{O}_{1}$ and $\mathrm{O}_{2}$. The results of comparison of the total powers between the hallucination-delusion group and the control group and those between the psychomotor excitement group and the control group are shown in Table 3 and 4, respectively. None of the total powers was significantly increased in either subgroup of patients. But the total powers were significantly decreased at 10 sections in the hallucination-delusion group : for the $\delta$ power at $\mathrm{C}_{3}, \mathrm{C}_{4}$ and $\mathrm{T}_{5}$ and for the $\alpha_{2}$ power at $\mathrm{F}_{3}, \mathrm{~F}_{4}, \mathrm{C}_{4}, \mathrm{~T}_{5}, \mathrm{P}_{4}, \mathrm{O}_{1}$ and $\mathrm{O}_{2}$, while at 17 sections in the psychomotor excitement group : for the 

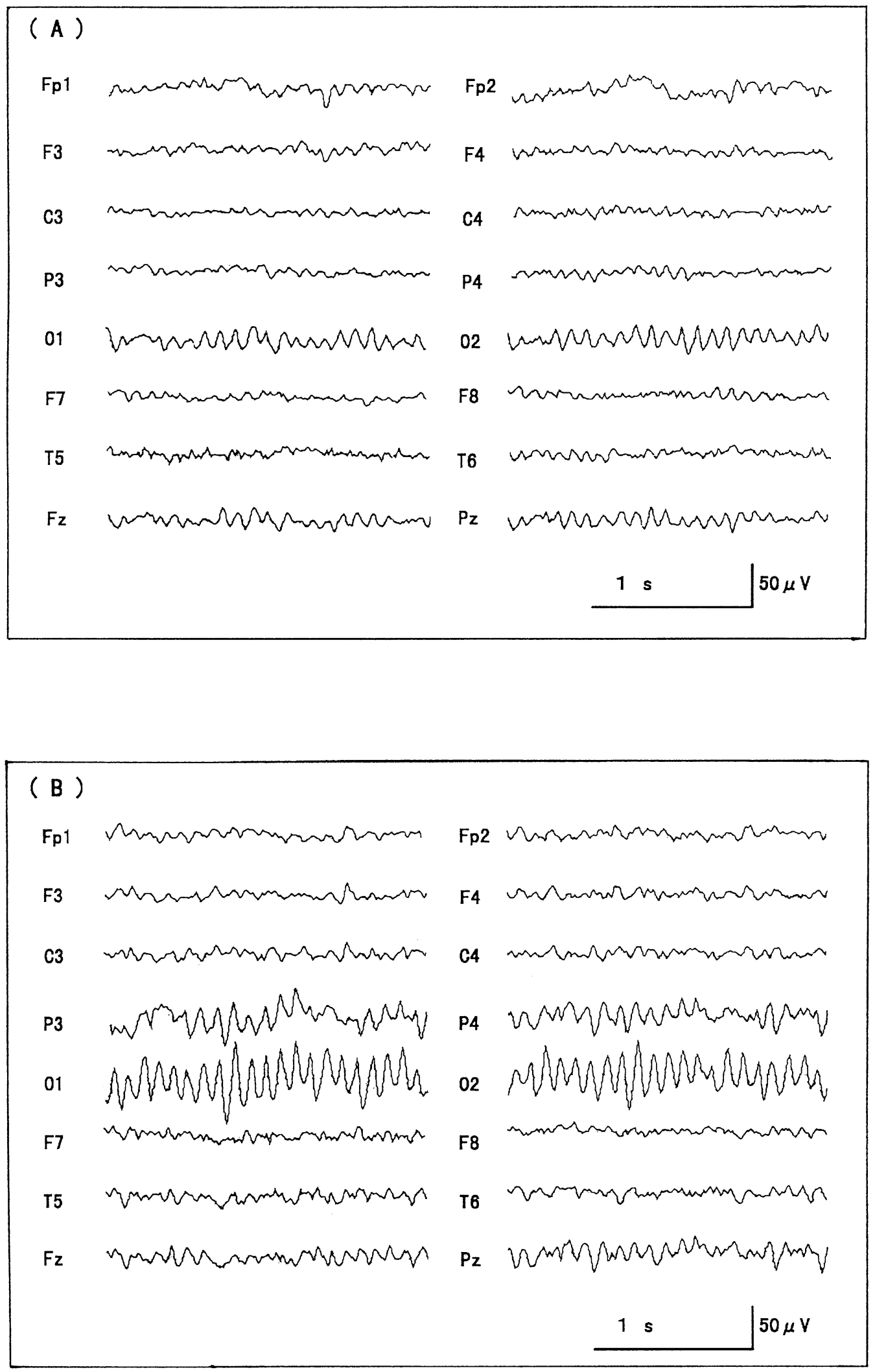

Fig. 1. Representative records of the background EEG activity at 16 locations in Case 6 with methamphetamine psychosis (A) and a control subject (B)

$\delta$ power at $\mathrm{F}_{3}, \mathrm{C}_{3}, \mathrm{C}_{4}, \mathrm{~T}_{5}$ and $\mathrm{T}_{6}$, for the $\theta$ power at $\mathrm{T}_{6}$, and for the $\alpha_{2}$ power at $\mathrm{Fp}_{1}, \mathrm{Fp}_{2}, \mathrm{~F}_{3}, \mathrm{~F}_{4}, \mathrm{C}_{4}, \mathrm{~T}_{5}, \mathrm{~T}_{6}, \mathrm{P}_{3}$, $\mathrm{P}_{4}, \mathrm{O}_{1}$ and $\mathrm{O}_{2}$. Furthermore, comparison of the total powers between the patient subgroups revealed that the $\alpha_{2}$ power in the psychomotor excitement group was significantly decreased at $\mathrm{F}_{7}, \mathrm{~F}_{8}$ and $\mathrm{T}_{6}$ than in the 
Neurophysiological Abnormalities of the Central Nervous System in Patients with Methamphetamine Psychosis

Table 2. Comparison of total power values between the methamphetamine psychosis group and the control group

\begin{tabular}{|c|c|c|c|c|c|c|c|c|c|c|c|c|c|c|c|c|}
\hline & $\mathrm{F}_{\mathrm{P} 1}$ & $\mathrm{~F}_{\mathrm{P} 2}$ & $\mathrm{~F}_{3}$ & $\mathrm{~F}_{4}$ & $\mathrm{~F}_{\mathrm{Z}}$ & $\mathrm{F}_{7}$ & $\mathrm{~F}_{8}$ & $\mathrm{C}_{3}$ & $\mathrm{C}_{4}$ & $\mathrm{~T}_{5}$ & $\mathrm{~T}_{6}$ & $\mathrm{P}_{3}$ & $\mathrm{P}_{4}$ & $\mathrm{P}_{\mathrm{Z}}$ & $\mathrm{O}_{1}$ & $\mathrm{O}_{2}$ \\
\hline$\delta$ band & & & & & & & & $*$ & $*$ & $*$ & $*$ & & & & & \\
\hline$\theta$ band & & & & & & & & & & & $*$ & & & & & \\
\hline$\alpha_{1}$ band & & & & & & & & & & & & & & & & \\
\hline$\alpha_{2}$ band & & & $*$ & $*$ & & & & & $*$ & $* *$ & $*$ & $*$ & $*$ & & $*$ & $*$ \\
\hline$\beta_{1}$ band & & & & & & & & & & & & & & & & \\
\hline$\beta_{2}$ band & & & & & & & & & & & & & & & & \\
\hline
\end{tabular}

Asterisk indicates a significantly decreased power value in the patient group. ${ }^{*}: \mathrm{P}<0.05,{ }^{* *}: \mathrm{P}<0.01$

Table 3. Comparison of total power values between the hallucination-delusion group and the control group

\begin{tabular}{|c|c|c|c|c|c|c|c|c|c|c|c|c|c|c|c|c|}
\hline & $\mathrm{F}_{\mathrm{P} 1}$ & $\mathrm{~F}_{\mathrm{P} 2}$ & $\mathrm{~F}_{3}$ & $\mathrm{~F}_{4}$ & $\mathrm{~F}_{\mathrm{Z}}$ & $\mathrm{F}_{7}$ & $\mathrm{~F}_{8}$ & $\mathrm{C}_{3}$ & $\mathrm{C}_{4}$ & $\mathrm{~T}_{5}$ & $\mathrm{~T}_{6}$ & $\mathrm{P}_{3}$ & $\mathrm{P}_{4}$ & $\mathrm{P}_{\mathrm{Z}}$ & $\mathrm{O}_{1}$ & $\mathrm{O}_{2}$ \\
\hline$\delta$ band & & & & & & & & $*$ & $*$ & $*$ & & & & & & \\
\hline$\theta$ band & & & & & & & & & & & & & & & & \\
\hline$\alpha_{1}$ band & & & & & & & & & & & & & & & & \\
\hline$\alpha_{2}$ band & & & $*$ & $*$ & & & & & $*$ & $* *$ & & & $*$ & & $*$ & $*$ \\
\hline$\beta_{1}$ band & & & & & & & & & & & & & & & & \\
\hline$\beta_{2}$ band & & & & & & & & & & & & & & & & \\
\hline
\end{tabular}

Asterisk indicates a significantly decreased power value in the patient group. ${ }^{*}: \mathrm{P}<0.05,{ }^{* *}: \mathrm{P}<0.01$

Table 4. Comparison of total power values between the psychomotor excitement group and the control group

\begin{tabular}{|c|c|c|c|c|c|c|c|c|c|c|c|c|c|c|c|c|}
\hline & $\mathrm{F}_{\mathrm{P}_{1}}$ & $\mathrm{~F}_{\mathrm{P} 2}$ & $\mathrm{~F}_{3}$ & $\mathrm{~F}_{4}$ & $\mathrm{~F}_{Z}$ & $\mathrm{~F}_{7}$ & $\mathrm{~F}_{8}$ & $\mathrm{C}_{3}$ & $\mathrm{C}_{4}$ & $\mathrm{~T}_{5}$ & $\mathrm{~T}_{6}$ & $\mathrm{P}_{3}$ & $\mathrm{P}_{4}$ & $\mathrm{P}_{\mathrm{Z}}$ & $\mathrm{O}_{1}$ & $\mathrm{O}_{2}$ \\
\hline$\delta$ band & & & $*$ & & & & & $*$ & $*$ & $*$ & $*$ & & & & & \\
\hline$\theta$ band & & & & & & & & & & & $*$ & & & & & \\
\hline$\alpha_{1}$ band & & & & & & & & & & & & & & & & \\
\hline$\alpha_{2}$ band & $*$ & $*$ & $*$ & $* *$ & & & & & $*$ & $* *$ & $*$ & $*$ & $*$ & & $*$ & $*$ \\
\hline$\beta_{1}$ band & & & & & & & & & & & & & & & & \\
\hline$\beta_{2}$ band & & & & & & & & & & & & & & & & \\
\hline
\end{tabular}

Asterisk indicates a significantly decreased power value in the patient group. ${ }^{*}: \mathrm{P}<0.05,{ }^{* *}: \mathrm{P}<0.01$

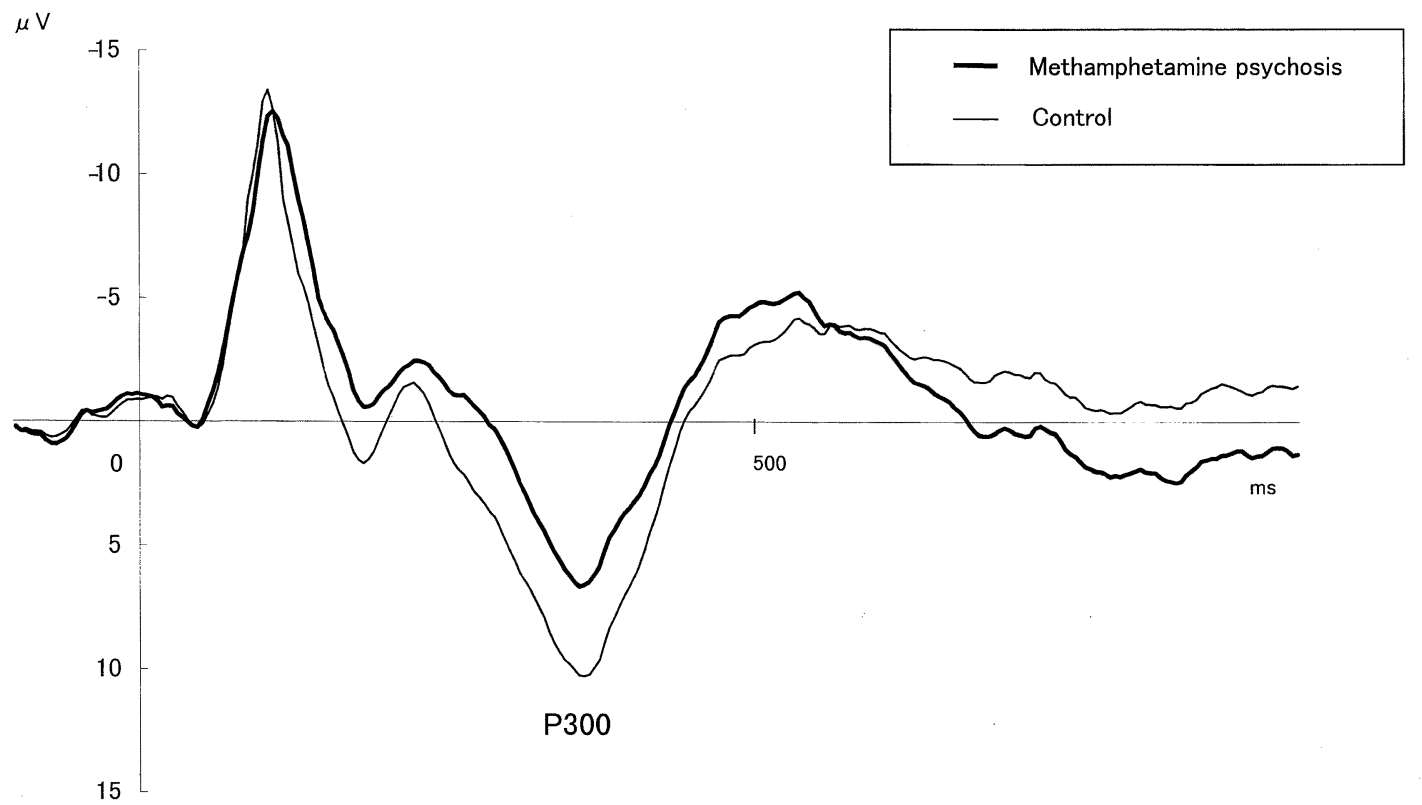

Fig. 2. Representative examples of the $\mathrm{P} 300$ waveform at $\mathrm{Cz}$ in Case 6 with methamphetamine psychosis and a control subject 
Table 5. The P300 latencies and amplitudes

\begin{tabular}{|c|c|c|c|c|}
\hline & \multicolumn{3}{|c|}{ Methamphetamine psychosis } & \multirow{2}{*}{$\begin{array}{l}\text { Control group } \\
(\mathrm{n}=35)\end{array}$} \\
\hline & $\begin{array}{l}\text { Methamphetamine } \\
\text { psychosis group } \\
(\mathrm{n}=17)\end{array}$ & $\begin{array}{l}\text { Hallucination- } \\
\text { delusion group } \\
\quad(n=10)\end{array}$ & $\begin{array}{l}\text { Psychomotor } \\
\text { excitement group } \\
(n=7)\end{array}$ & \\
\hline $\mathrm{F}_{z}$ Latency $(\mathrm{ms})$ & $329.3 \pm 27.2$ & $327.7 \pm 27.3$ & $331.5 \pm 29.2$ & $333.9 \pm 24.3$ \\
\hline $\mathrm{C}_{Z}$ Latency (ms) & $331.6 \pm 26.7$ & $330.1 \pm 24.7$ & $333.7 \pm 31.2$ & $334.0 \pm 25.7$ \\
\hline $\mathrm{P}_{Z}$ Latency $(\mathrm{ms})$ & $339.1 \pm 30.8$ & $339.4 \pm 28.4$ & $338.7 \pm 36.2$ & $335.9 \pm 26.9$ \\
\hline $\mathrm{F}_{Z}$ Amplitude $(\mu \mathrm{V})$ & $3.32 \pm 3.94^{* *}$ & $2.58 \pm 3.22 *$ & $4.37 \pm 4.86$ & $7.48 \pm 5.02$ \\
\hline$C_{Z}$ Amplitude $(\mu \mathrm{V})$ & $5.55 \pm 5.23^{*}$ & $4.85 \pm 5.45^{*}$ & $6.56 \pm 5.14$ & $10.13 \pm 6.21$ \\
\hline $\mathrm{P}_{\mathrm{Z}}$ Amplitude $(\mu \mathrm{V})$ & $7.74 \pm 4.84^{*}$ & $7.62 \pm 4.18^{*}$ & $7.92 \pm 6.02$ & $11.88 \pm 5.74$ \\
\hline
\end{tabular}

All data are shown as mean values \pm SD. Comparisons of methamphetamine psychosis group vs control group, hallucinationdelusion group vs control group, and psychomotor excitement group vs control group. ${ }^{*}: \mathrm{p}<0.05,{ }^{* *}: \mathrm{p}<0.01$

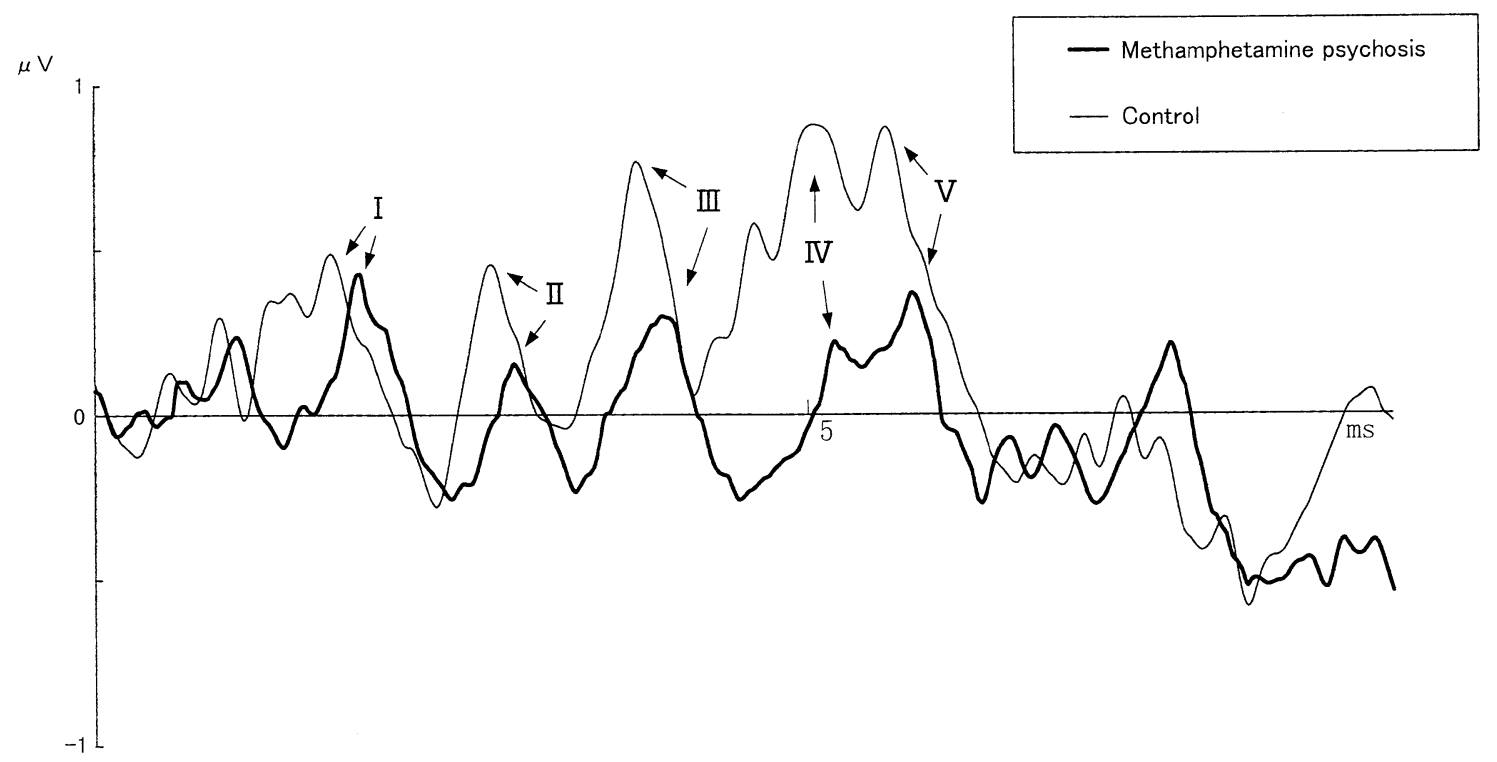

Fig. 3. Representative examples of the ABR waveform in Case 6 with methamphetamine psychosis and a control subject under the left ear stimulation condition

hallucination-delusion group $(\mathrm{p}<0.05$, respectively. The table is not shown). Thus it is clear that the abnormalities were more widely distributed and profound in the latter group than in the former.

\section{P300}

Representative examples of the P300 waveform in a patient and a control subject are shown in Fig. 2. A decreased P300 amplitude in the patient is clearly observed. Mean values $\pm S D$ for the button-press response time were $415.9 \pm 106.7 \mathrm{~ms}$ in the methamphetamine psychosis group and $375.4 \pm 95.6 \mathrm{~ms}$ in the control group. The difference between the groups was not significant. Nor were any significant differences observed when the patients were divided into the subgroups. The correct response rates were almost $100 \%$ in both groups, with the difference between them being insignificant.

The results of measuring P300 latencies and amplitudes at $\mathrm{Fz}, \mathrm{Cz}$, and $\mathrm{Pz}$ are shown in Table 5. Compar- ing the methamphetamine psychosis group with the control group, there were no significant differences in latencies at $\mathrm{Fz}, \mathrm{Cz}$, or $\mathrm{Pz}$, but the amplitudes were significantly decreased at all locations in the patient group ( $\mathrm{Fz}: \mathrm{p}<0.01, \mathrm{Cz}, \mathrm{Pz}: \mathrm{p}<0.05$ ). Comparing the patient subgroups with the control group, there was no significant difference in latency at all in either subgroup. The amplitude was significantly decreased at all locations in the hallucination-delusion group $(\mathrm{p}<$ 0.05 ), but no significant difference was observed at any of the locations in the psychomotor excitement group. No significant correlations were found between the duration of methamphetamine abuse and the P300 latency or amplitude at any of the locations. Nor were any significant correlations observed between the dose of antipsychotic drugs and P300 variables.

\section{ABR}

Representative examples of the ABR waveform in a patient and a control subject are shown in Fig. 3. 
Table 6. ABR latencies under the left ear stimulation condition

\begin{tabular}{|c|c|c|c|c|}
\hline & \multicolumn{3}{|c|}{ Methamphetamine psychosis } & \multirow{2}{*}{$\begin{array}{l}\text { Control group } \\
\quad(\mathrm{n}=35)\end{array}$} \\
\hline & $\begin{array}{l}\text { Methamphetamine } \\
\text { psychosis group } \\
(\mathrm{n}=17)\end{array}$ & $\begin{array}{l}\text { Hallucination- } \\
\text { delusion group } \\
\quad(n=10)\end{array}$ & $\begin{array}{l}\text { Psychomotor } \\
\text { excitement group } \\
(n=7)\end{array}$ & \\
\hline wave I (ms) & $1.52 \pm 0.17$ & $1.51 \pm 0.21$ & $1.55 \pm 0.93$ & $1.46 \pm 0.10$ \\
\hline wave II (ms) & $2.89 \pm 0.23$ & $2.97 \pm 0.23^{*}$ & $2.79 \pm 0.20$ & $2.81 \pm 0.15$ \\
\hline wave III (ms) & $3.90 \pm 0.22$ & $3.83 \pm 0.20$ & $3.98 \pm 0.23$ & $3.85 \pm 0.16$ \\
\hline wave IV (ms) & $5.00 \pm 0.17$ & $5.01 \pm 0.21$ & $4.98 \pm 0.84$ & $5.03 \pm 0.19$ \\
\hline wave V (ms) & $5.97 \pm 0.24^{* *}$ & $6.06 \pm 0.21^{* *}$ & $5.85 \pm 0.23$ & $5.78 \pm 0.13$ \\
\hline $\mathrm{V}-\mathrm{I} \quad(\mathrm{ms})$ & $4.45 \pm 0.28^{*}$ & $4.56 \pm 0.21^{* *}$ & $4.30 \pm 0.31$ & $4.31 \pm 0.15$ \\
\hline
\end{tabular}

All data are shown as mean values \pm SD. Comparisons of methamphetamine psychosis group vs control group, hallucinationdelusion group vs control group, and psychomotor excitement group vs control group. ${ }^{*}: \mathrm{p}<0.05,{ }^{* *}: \mathrm{p}<0.01$

Table 7. ABR latencies under the right ear stimulation condition

\begin{tabular}{|c|c|c|c|c|}
\hline & \multicolumn{3}{|c|}{ Methamphetamine psychosis } & \multirow{2}{*}{$\begin{array}{l}\text { Control group } \\
(\mathrm{n}=35)\end{array}$} \\
\hline & $\begin{array}{l}\text { Methamphetamine } \\
\text { psychosis group } \\
(\mathrm{n}=17)\end{array}$ & $\begin{array}{l}\text { Hallucination- } \\
\text { delusion group } \\
\quad(\mathrm{n}=10)\end{array}$ & $\begin{array}{l}\text { Psychomotor } \\
\text { excitement group } \\
(\mathrm{n}=7)\end{array}$ & \\
\hline wave I (ms) & $1.49 \pm 0.11$ & $1.50 \pm 0.12$ & $1.47 \pm 0.10$ & $1.44 \pm 0.84$ \\
\hline wave II (ms) & $2.88 \pm 0.18$ & $2.92 \pm 0.14$ & $2.83 \pm 0.23$ & $2.80 \pm 0.16$ \\
\hline wave III (ms) & $3.93 \pm 0.21$ & $3.91 \pm 0.21$ & $3.96 \pm 0.23$ & $3.82 \pm 0.19$ \\
\hline wave IV (ms) & $5.08 \pm 0.34$ & $5.20 \pm 0.19^{* *}$ & $4.93 \pm 0.44$ & $4.96 \pm 0.21$ \\
\hline wave V (ms) & $5.95 \pm 0.15^{* *}$ & $5.98 \pm 0.15^{* *}$ & $5.91 \pm 0.14^{*}$ & $5.76 \pm 0.18$ \\
\hline $\mathrm{V}-\mathrm{I}(\mathrm{ms})$ & $4.46 \pm 0.16^{* *}$ & $4.47 \pm 0.15^{*}$ & $4.44 \pm 0.18$ & $4.32 \pm 0.18$ \\
\hline
\end{tabular}

All data are shown as mean values \pm SD. Comparisons of methamphetamine psychosis group vs control group, hallucinationdelusion group vs control group, and psychomotor excitement group vs control group. ${ }^{*}: \mathrm{p}<0.05,{ }^{* *}: \mathrm{p}<0.01$

Mean values for the peak latencies of waves I to $\mathrm{V}$ and the V-I inter-peak latency under the left ear stimulation condition and the right ear stimulation condition in each group of subjects are shown in Table 6 and 7 , respectively. Comparing the methamphetamine psychosis group with the control group under the left ear stimulation condition, the wave $\mathrm{V}$ and $\mathrm{V}$ - I inter-peak latencies were significantly increased in the patient group (wave $\mathrm{V}: \mathrm{p}<0.01$, waves $\mathrm{V}-\mathrm{I}: \mathrm{p}<0.05$ ). Under the right ear stimulation condition, the wave $\mathrm{V}$ and V-I inter-peak latencies were also significantly increased in the patient group (wave $\mathrm{V}$ and wave $\mathrm{V}$ - I : p <0.01). Comparison of the latencies between the patient subgroups and the control group under the left ear stimulation condition showed that the wave II, wave $\mathrm{V}$ and $\mathrm{V}$ - I inter-peak latencies were significantly increased in the hallucination-delusion group (wave II : $\mathrm{p}<0.05$, wave $\mathrm{V}$ and wave $\mathrm{V}-\mathrm{I}: \mathrm{p}<0.01$ ), but no significant delay of latency was found in the psychomotor excitement group. Under the right ear stimulation condition, the wave IV, wave $\mathrm{V}$ and $\mathrm{V}$ - I inter-peak latencies were both significantly increased in the hallucination-delusion group (wave IV and wave $\mathrm{V}: \mathrm{p}<0.01$, waves $\mathrm{V}-\mathrm{I}: \mathrm{p}<0.05$ ). In the psychomotor excitement group a significant increase was observed only in the wave $V$ latency $(p<0.05)$. There were no significant correlations between any ABR wave latencies and the duration of methamphetamine abuse or the dose of antipsychotic drugs.

\section{DISCUSSION}

\section{Background EEG activity}

The EEG is one of the most commonly used physiological tests, and the overall functional condition of the brain, especially the cortex, can be determined by evaluating the background EEG activity. Information on the background activity can be gleaned by visual inspection, but frequency analysis gives more detailed quantitative data. Recently, a frequency analysis by fast Fourier transformation has been performed in a variety of fields. However, no studies have so far been reported on the frequency analysis of the EEG in patients with methamphetamine psychosis. There are only a few reports ${ }^{25,26)}$ on the frequency analysis of the background EEG activity in rats given an acute dose of amphetamine with the results contradicting each other.

The present study revealed for the first time that in the patients chronically intoxicated with methamphetamine the $\delta$ power was significantly decreased at 4 locations, while the $\theta$ power at 1 location, and the $\alpha_{2}$ power at 9 locations. Although all the patients but one were on antipsychotic drugs when investigated, it seems difficult to regard the EEG abnormalities as the drug effects, since the effects of antipsychotic drugs on the background EEG activities are generally of a very mild degree causing a decrease in $\alpha$ waves but an 
increase in slow waves ${ }^{27}$. The decrease of slow waves, especially of the $\delta$ band, is usually not found in the fast Fourier transformation. However, Lifshitz et al. ${ }^{28)}$ reported that a decrease of slow waves was observed in schizophrenia and suggested that a decrease of slow waves was observed in schizophrenia and regarded that it might reflect a state of hyperarousal. It is possible that patients with methamphetamine psychosis may also be in the same state. Thus the unique findings in the present study of a decrease in the total power seem to reflect the pathology of methamphetamine psychosis.

It is generally believed that the origin of background EEG activity is mainly the cerebral cortex. Thus a decrease in the power of background EEG may represent the cortical dysfunction. There was a remarkable difference between the patient subgroups in the number of significantly reduced total power values and of locations of lead where the reduced power values were observed. The hallucination-delusion group showed 10 reduced power values at 8 locations as compared with controls, whereas the psychomotor excitement group 19 reduced power values at 14 locations (17 power values at 12 locations vs controls plus additional 2 power values at 2 locations vs hallucination-delusion group). Therefore, it may follow that the cortical dysfunction is much more widespread and profound in the psychomotor excitement group than in the hallucination-delusion group. It may also follow that to develop such symptoms as hallucinations and delusions the cortical function or integrity must be maintained on a certain level, and a further progression of dysfunction precipitates a gross excitement of catatonic nature.

\section{2. $\mathbf{P 3 0 0}$}

P300 of the event-related potentials was discovered by Sutton et al. ${ }^{29)}$ in 1965 , and it provides a good method to test some aspects of cognitive function. A large positive potential of P300 is considered to be generated by the multiple structures located in the medial temporal and parietal lobes, including the hippocampus ${ }^{30 \sim 33)}$. The relationship between P300 amplitude and cognitive processes has been established, while P300 latency reflect the speed of stimulus classification $^{34)}$. Deseases of cognition can produce P300 latency and/or amplitude changes ${ }^{34)}$. A large number of studies $\left.{ }^{35} 39\right)$ have been published on P300 in patients with schizophrenia, since cognitive disorders are central in schizophrenia. Although the cognitive abnormalities in methamphetamine psychosis are also central, P300 studies in this condition have so far been reported only by Iwanami's group ${ }^{21,22}$. In view of the similar symptomatology in both conditions, it seems of value to perform more studies on P300 in methamphetamine psychosis to compare the findings with those in schizophrenia.

A decrease in P300 amplitude in patients with methamphetamine psychosis was found in the present study. The abnormality was limited to the hallucination-delusion group, i.e. the patients who had experienced hallucinations and delusions, and was not found at all in the other group of patients who had never experienced hallucinations or delusions before. The P300 amplitude reduction was not related to the duration of methamphetamine abuse or to the dose of antipsychotic medication. Previous studies by Iwanami et al. ${ }^{21,22)}$ reported that there was a significant increase in P300 latency as well as a significant decrease in P300 amplitude in patients. So their findings differ from ours, since we found no prolongation of the latency. The reason for this discrepancy is unknown, but it may be worthwhile to note that the similar discrepancy is often found as to the P300 latency prolongation in the studies ${ }^{38,39)}$ with schizophrenia patients. Meanwhile it may also be noteworthy that as to the P300 amplitude reduction there is no discrepancy at all among the studies ${ }^{35 \sim 39)}$ in schizophrenia as well as the studies in methamphetamine psychosis.

At present, the functional significance of the P300 is not clear. However, the remarkable fact that the decrease in P300 amplitude was selectively found in the hallucination-delusion group strongly suggest that the P300 abnormality takes part in the pathogenesis of hallucinations and delusions.

\section{ABR}

The ABRs are very early components of small potentials that are evoked in the brainstem by auditory stimuli. They were recorded for the first time in cats by Jewett ${ }^{40)}$ in 1970 and in humans by Lev and Sohmer ${ }^{41)}$ in 1972. ABRs are expressed in an extremely stable manner, unaffected by changes in consciousness level or by drugs ${ }^{42)}$, and they are currently in wide clinical use. The source of each wave component is known : the cochlear nerve for wave I, the cochlear nucleus for wave II, the superior olivary nucleus for wave III, the lateral lemniscus and the superior olivary complex for wave IV, and the inferior colliculus for wave V. Their latencies are widely used as indicators for the speed of conduction and/or transmission of a signal in the central nervous system. However, no studies have so far been reported on the ABR latencies in patients with methamphetamine psychosis.

That the ABR latencies were increased in patients 
with methamphetamine psychosis were found for the first time in the present study. The increase mostly concentrated on wave V latency and waves V- I interpeak interval, and was also mostly confined to the hallucination-delusion group. The latency prolongation of was not correlated with the duration of methamphetamine abuse or with the dose of antipsychotic drugs. The pathogenesis of latency prolongation or abnormal conduction and/or transmission in chronic methamphetamine intoxication is unknown. However, it might be relevant to the morphological abnormalities reported by Kato et $\mathrm{al}^{7}$. They electron-microscopically studied brains of guinea pigs given chronic doses of methamphetamine and found thickening and fusion of membrane and abnormal shapes of synaptic vesicles in the nerve fibers and nerve endings in various parts of the brain.

The finding that the latency prolongation was mostly confined to the hallucination-delusion group suggests that the brainstem dysfunction is heavily involved in the pathogenesis of hallucinations and delusions.

\section{ACKNOWLEDGEMENTS}

The authors would like to thank Prof. Yukiteru Machiyama, Department of Neuropsychiatry, Gunma University School of Medicine, for his guidance and encouragement. The authors would like to thank to Drs. M. Baba and M. Takei and the other staffs of Gunma Prefectural Psychiatric Medical Center for their cooperation during this study.

\section{REFERENCES}

1) Machiyama $Y$. Amphetamine intoxication. In : Uraguchi K, Ueno Y, Kasuya Y, et al. (eds) : Toxicology. Tokyo : Chijin-Shokan, 1978 : 346367 (in Japanese).

2) Yanagida T. Intoxication. In : Sato $Y$, Takahashi R. (eds) : Current Encyclopedia of Psychiatry 22A Psychopharmacology I . Tokyo : Nakayama-Shoten, 1980: 169-184 (in Japanese).

3) Takahashi Y, Akabane Y. Brain hexokinase activity. Arch Gen Psychiatry 1960 ; 3: 674-681.

4) Yokoi S, Akiyama Y. Histopathological studies on intoxication due to methamphetamine. Kitakanto Med J 1958; 8 : 296-303 (in Japanese).

5) Miyakawa $T$, Sumiyoshi S, Deshimaru M, et al. An electron-microscopic study on the mechanism of mental disturbances in experimentally induced chronic methamphetamine administration. Psychiatr Neurol Jpn 1969; 71: 548-560 (in Japanese).

6) Sumiyoshi S. Electron microscopic studies on the viscera of experimental chronic methamphetamine poisoning. Psychiatr Neurol Jpn 1969; 71 : 844855 (in Japanese).

7) Kato N, Kashiba A, Kariyama H. The histochemical study of the brain of methamphetamine intoxicated animals. Inanaga K, Toru M. (eds) : What Is Schizophrenia? II. Tokyo : Tokyodaigaku-Shuppankai, 1987 : 142-156.

8) Machiyama Y, Utena H, Kikuchi M. Behavioural disorders in Japanese monkeys produced by the long-term administration of methamphetamine. Proc Japan Acad 1970; 46 : 738-743.

9) Utena H, Machiyama U, Kikuchi M. Behavioral disorders in monkeys produced by the long-term administration of methamphetamine. An animal model for schizophrenia. Movie film, $16 \mathrm{~mm}$, 33min, sound (English narration). Tokyo: Eisai Co.Ltd., 1970.

10) Machiyama Y. Experimental psychosis. In : Yokoi S, Sato I, Miyamoto T.(eds) : Schizophrenia. Tokyo: Igaku-Shoin, 1975: 451-474 (in Japanese).

11) Akiyama K, Sato M, Kashihara K, et al. Lasting changes in high affinity ${ }^{3} \mathrm{H}$-spiperone binding to the rat striatum and mesolimbic area after chronic methamphetamine administration: Evaluation of dopaminergic and serotonergic receptor components. Biol Psychiatry 1982; 17 : 1389-1402.

12) Ohtuki S, Sato M. In. The clinical and experimental study for the mechanism of exacerbation of schizophrenia. Shimazono Y, Inanaga K.(eds) : What Is Schizophrenia ? Tokyo: TokyodaigakuShuppankai, 1984 : 83-104 (in Japanese).

13) Tadokoro $S$, Kuribara $H$, Hayashi $T$. In. The behavioral pharmacology of the reverse tolerance induced by repeated administration of methamphetamine. Shimazono Y, Inanaga K.(eds) : What Is Schizophrenia? Tokyo: TokyodaigakuShuppankai, 1984 : 128-136 (in Japanese).

14) Angrist BM, Gershon S. The phenomenology of experimentally induced amphetamine psychosis: Preliminary observations. Biol Psychiatry 1970 ; 2 : 95-107.

15) Griffith JD, Cavanaugh J, Held J, et al. Dextroamphetamine: Evaluation of psychomimetic properties in man. Arch Gen Psychiatry 1972 ; 26: 97-100.

16) Bell DS. The experimental reproduction of amphetamine psychosis. Arch Gen Psychiatry 1973; 29 : 35-40.

17) Utena H, Ezoe T, Kato N. Biochemical studies on addiction due to $\beta$-phenylisopropylmethylamine. ( I) Tissue distribution and excretion of the 
amine. Psychiatr Neurol Jpn 1955; 57 : 115-124 (in Japanese).

18) Utena H, Ezoe T, Kato N. Biochemical studies on addiction due to $\beta$-phenylisopropylmethylamine. (II) Effect on glucose metabolism in brain tissue. Psychiatr Neurol Jpn 1955; $57: 124-130$ (in Japanese).

19) Kojima T, Matsushima E, Iwama H, et al. Visual perception process in amphetamine psychosis and schizophrenia. Psychopharmacol Bull 1986; 22 : 768-773.

20) Kojima T. In. The study on eye movements of methamphetamine psychotic patients. Simazono Y.(eds) : The Eyes and Heart. Tokyo: SozoShuppan, 1991 : 213-218 (in Japanese).

21) Iwanami A, Suga I, Yamada H, et al. P300 components of event-related potentials in methamphetamine psychosis. Jpn J Clin Psychiatry 1990 ; 32: 719-725 (in Japanese with English abstract).

22) Iwanami A, Kato N, Nakatani Y. P300 in methamphetamine psychosis. Biol Psychiatry 1991; 30: 726-730.

23) Toru M. The Pharmacology of Schizophrenia. Tokyo : Chugai-Igakusha, 1983: 1-260 (in Japanese).

24) The commission for the tests of evoked potentials. A guide for measurement of evoked potentials. Jpn J EEG and EMG 1985; 13: 97-104 (in Japanese).

25) Glatt A, Duerst T, Mueller B, et al. EEG evaluation of drug effects in the rat. Neuropsychobiology $1983 ; 9$ : 163-166.

26) Diedrich M, Schulz S, Wetzel W. Effects of [des-Tyr-D-Phe3] beta-casomorphin (2-5) on cortical EEG power spectra in rats. Peptides $1994 ; 15: 667-670$.

27) Shagass C. An electrophysiological view of schizophrenia. Biol Psychiatry 1976; 11: 3-30.

28) Lifshitz K, Lee KL, Susswein S. Long-term replicability of EEG spectra and auditory evoked potentials in schizophrenic and normal subjects. Neuropsychobiology 1987 ; 18 : 205-211.

29) Sutton S, Braren M, Zulin J. Evoked potential correlated of stimulus uncertainty. Science 1965 ; 150: 1187-1188.

30) Nakagome K, Iwanami A, Takazawa S, et al. Recent advances in the neural mechanism of information processing in the brain revealed by ERP and ERF. Jpn J Clin Psychiatry 1996 ; 25 : 397409 (in Japanese).
31) Halgren E, Squires NK, Wilson CL, et al. Endogenous potentials generated in the human hippocampal formation and amygdala by infrequent events. Science $1980 ; 210$ : 803-805.

32) Kaga K, Harrison JB, Butcher LL, et al. Cat P300 and cholinergic septohippocampal neurons: depth recordings, lesions and cholins acetyltransferase immunohistochemistry. Neurosci Res 1992 ; 13: 53-71.

33) Nakajima Y, Miyamoto K, Kikuchi M. Estimation of neural generators of cognitive potential P300 by dipole tracing method. Brain and Nerve (Tokyo) 1994; 46: 1059-1065 (in Japanese with English abstract).

34) Polich J. P300 in clinical applications : meaning, method, and measurement. In : Niedermeyer E, Lopes da Silva F. (eds). Electroencephalography. 3rd ed. Baltimore, Munich : Urban and Schwarzenberg; 1995 : 1005-1018.

35) Levit RA, Sutton S, Zubin J. Evoked potential correlates of information processing in psychiatric patients. Psychol Med 1973; 3 : 487-494.

36) Roth WT, Horvath TB, Pfefferbaum A, et al. Event-related potentials in schizophrenics. Electroencephalo Clin Neurophysiol 1980; 48 : 127-139.

37) Roth WT, Pfefferbaum A, Horvath TB, et al. P3 reduction in auditory evoked potentials of schizophrenics. Electroencephalo Clin Neurophysiol $1980 ; 49$ : 497-505.

38) Machiyama Y, Shiihara Y. Schizophrenia and event-related potentials. Psychiatr Neurol Jpn 1985 ; 87 : 936-943 (in Japanese).

39) Souza VB, Muir WJ, Walker MT, et al. Auditory P300 event-related potentials and neuropsychological performance in schizophrenia and bipolar affective disorder. 1995; 37 : 300-310.

40) Jewett DL. Volume-conducted potentials in response to auditory stimuli as detected by averaging in the cat. Electroencephalo Clin Neurophysiol $1970 ; 28$ : 609-618.

41) Lev A, Sohmer H. Sources of averaged neural responses recorded in animal and human subjects during cochlear audiometry (electrocochleogram). Arch Klin Exp Ohren Nasen Kehlkopfheilkd 1972; 201 : 79-90.

42) Hashimoto I, Ishiyama Y. Localizing brainstem lesions with brainstem auditory evoked responses. Clinical EEG (Osaka) 1980;22:42-52 (in Japanese). 